\title{
Evaluation of Charu Prepared from Acalypha Indica L- An Important Medicinal Plant of Traditional Siddha System Useful in Treating Skin Diseases
}

\author{
Umate S K ${ }^{1}$, V R Marathe ${ }^{1, *}$, P V Pawar ${ }^{2}$ \\ ${ }^{1}$ PG Department of Botany, NES Science College, India \\ ${ }^{2}$ Madhavrao Patil Arts, Commerce \& Science College, India
}

Received January 24, 2020; Revised March 16, 2020; Accepted March 28, 2020

Copyright $\odot 2020$ by authors, all rights reserved. Authors agree that this article remains permanently open access under the terms of the Creative Commons Attribution License 4.0 International License

\begin{abstract}
Siddha system of medicine is practiced in regions of South India. The eighteen Siddhars were the men who achieved supreme knowledge in the field of medicine, yoga and tap, since then this system of medicine developed. Acalypha indica is an important medicinal plant mentioned in Siddha literature. In the present study, Charu prepared from raw powder of leaves of this plant were evaluated by using different techniques like Fourier Transform Infrared (FTIR) Spectroscopy analysis for determination of associated functional group, Inductively Coupled Plasma Atomic Emission Spectroscopy (ICP-AES) for the quantification of trace and heavy elements and antifungal activity of Charu were tested. FTIR analysis showed the broad peaks for numerous functional groups like alkanes, alkynes, alkyl halide, aromatics, alkaloid etc. Elemental analysis from this plant shows good results for most of trace as well as heavy elements which have great significance in diet. Plant product Charu shows good antifungal activity against four different pathogenic skin disease causing fungi and hence the formulation can be used to treat dermal infections.
\end{abstract}

Keywords Antifungal Activity, FTIR, ICP-AES, Siddha System

\section{Introduction}

The term Siddha means achievement and Siddhars were saintly personality who attained proficiency in medicine through practice of bhakti and yoga. According to traditional Indian belief lord Shiva unfolded the knowledge of medicine to his wife Parvati which was then passed to Siddhars and known as Siddha system of medicine. This is the system of pre-Vedic period identified with Dravidian culture and is largely therapeutic in nature. Like Ayurveda, this system believes three humours i.e. vatta, pitta and kapha and all objects of universe are made up of five basic elements called Panchmahabhuta namely earth, water, sky, fire and air. In this system identification of cause of disease is done by pulse reading called Nadi pariksha, colour of body, tone of voice, urine examination etc. the literature of this system mostly available in Tamil language. Different treatments were mentioned in this system, the material medica of Siddha system of medicine based on metal and mineral origin. The drugs used in disease treatment are herbal formulations with collective effects. Some important medicinal plants used in this system are Papever somniferum, Euphorbia nerifolia, Aloe barbandensis, etc [1].

The Leaves, roots, stalk and flowers of Acalypha indica are used in Siddha System of Medicine for its medicinal properties. According to Siddha Materia medica the leaf powder when given in the dose of $950 \mathrm{mg}$ to $1300 \mathrm{mg}$, cures respiratory diseases. The leaf juice when mixed with Neem oil and applied to the inner part of children's tongue with the help of quill, induces vomiting and acts as expectorant. Its other actions include cathartic, anthelmintic, emetic, anodyne and wound healing properties [2]. Whole plant is used for asthma, pneumonia, bronchitis and rheumatism [3]. It is useful in treatment of skin disease, snakebite $[4,5]$. The leaf extract has been reported to possess various properties such as antimicrobial, antibacterial, antifungal, antioxidant and antidiabetic activities $[6,7,8,9,10]$. It is an important wild edible plant with prominent nutraceutical values [11]. Extracts of leaves called "Charu” obtained by grinding them and is used in treating different fungal infections of skin [12]. Nowadays many skin related infectious diseases are spreading, specifically the high populated countries like India and hence it is very important to develop quick remedy for such infectious diseases. 
Acalypha indica proved to be best herbal medicine for various disease including skin diseases therefore an ideal formulation prepared from this plant is used to treat such skin diseases. There is a need of more sophisticated testing methods for pharmacological, toxicological and microbiological activities for determining quality of the herbal formulations. It is, therefore, essential that definite and accurate analytical methods be available to follow consistency and quality of herbal drugs, so that these products exhibit the desired medicinal effects. WHO specifies guidelines for the assessment of the efficacy and quality of herbal drugs as a prerequisite for global harmonization [13].

Major group of pathogen causing skin diseases are moulds and yeast fungi. From simple allergy to severe skin infections are caused by variety of fungal pathogen. Onychomycosis is one of the common dermatological infections in all over world which is caused mainly by dermatophytes but occasionally by non dermatophytic fungi like Aspergillus niger, Aspergillus flavus, Fusarium spp. and Acremonium spp. $[14,15,16]$. Cutaneous aspergillosis is second most common fungal infection next to candidiasis caused by Aspergillus spp.

Immune system of body failed to prevents the pathogens from causing illness when immunity is week due to cancer, HIV. The infectious organisms get the opportunity to invade and cause successive infection. Therefore, nondermatophytic fungi like Aspergillus spp., Fusarium spp., Penicillium spp., etc present in air, soil can cause such opportunistic infection to immune-deficient individual. It is very needful to have some primary responsive drug against such pathogen. Traditional medical systems like Ayurveda, Unani and Siddha have mentioned the herbal remedies to protect and prevent from such invasive diseases caused by nondermatophytic fungi. Aspergillus spp, Fusarium spp. and Penicilium spp. are very common fungi but have potential to cause cutaneous infection to human.

Present work deals with Evaluation of herbal formulation "Charu" from the raw leaf powder of Acalypha indica for its quality assessment approach which include FTIR analysis for determination of associated functional group, ICP-AES for the quantification of trace and heavy elements and antifungal activity against some nondermatophytic fungi like Aspergillus niger, Aspergillus flavus, Fusarium moneliforme and Penicillium chrysogenum.

\section{Materials and Methods}

\subsection{Collection and Identification of Plant Materials}

Fresh plant material of Acalypha indica L. was collected from different non polluted localities of Nanded district. It was identified at PG department of botany by using standard flora [17] and herbarium specimen is deposited at
WRO, BSI Pune.

\subsection{Preparation of Herbal Drug}

Extract of fresh leaves obtained by homogenizing them in mortar and pestle by adding little water which is followed by warm heat to the extract. This herbal formulation is called "Charu" according to traditional Siddha system of medicine [18].

\subsection{FTIR Analysis of Charu Prepared from Leaves of Acalypha indica}

Fourier Transform Infrared Spectrophotometer (FTIR) is perhaps the most powerful tool for identifying the types of chemical bonds (functional groups) present in compounds. The wavelength of light absorbed is characteristic of the chemical bond as can be seen in the annotated spectrum. By interpreting the infrared absorption spectrum, the chemical bonds in a molecule has been determined. Dried Charu was used for FTIR analysis. 10 $\mathrm{mg}$ of the dried Charu powder was encapsulated in $100 \mathrm{mg}$ of $\mathrm{KBr}$ pellet, in order to prepare translucent sample discs. The powdered sample of each plant specimen was loaded in FTIR spectroscope (Shimadzu, IR Affinity 1, Japan).

\subsection{Estimation of Some Trace and Heavy Elements from Charu Prepared from Leaves of Acalypha indica}

Prepared herbal drug Charu was hydrolysed by strong acid and analysed with ICP-AES. All spectrometric measurements were performed with ICP spectrometer (Arcos from M/S Spectro Germany). The software used was smart analyser vision 5.01.0921. The detector is Charge Couple Device (CCD). Samples were analysed in triplicate and mean value of concentrations for each elements are given along with standard deviation.

\subsection{Antifungal Activity of Charu Prepared from Leaves of Acalypha indica}

The Charu is dissolved in DMSO and incorporated into the molten agar at a desired final concentration ( $5 \%$ \& $10 \%$ in DMSO) and mixed well. Then, the medium is poured into Petri dishes. After overnight pre-incubation, the inoculation can be done by a mycelia disc of $5 \mathrm{~mm}$, which is deposited in the four corners of the plate, four pathogenic fungal strains were studied for this analysis are Aspergillus flavus, Aspergillus niger, Fusarium moneliforme and Penicillium chrysogenum and the results were compared with standard positive control Griseofulvin. Further incubation under suitable conditions for the given fungal strain tested, the diameters of fungal growth in control and sample plates are measured, and the antifungal effect is estimated by the following formula [19]:

Antifungal activity \% = (Dc - Ds / Dc) $x 100$

Where, Dc = diameter of growth in control plate

Ds = diameter of growth in the plate containing tested herbal drug. 


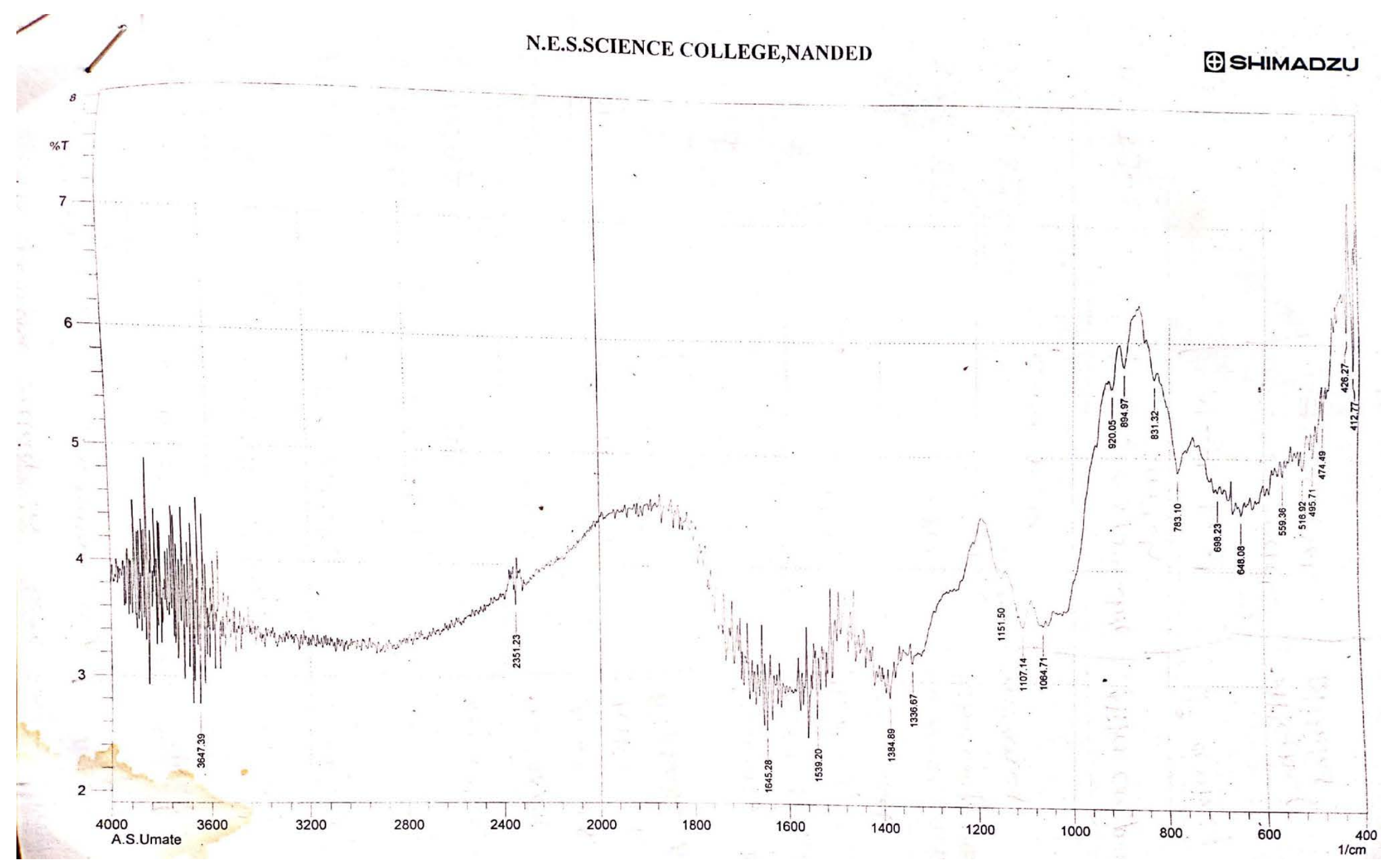

Graph 1. IR spectrum for charu drug prepared from leaves of Acalypha indica 


\section{Results}

\subsection{FTIR Analysis of Charu Prepared from Leaves of Acalypha indica}

FTIR analysis of plant powder was done and it shows number of peaks within the range of 1000 peak values. The result has showed in Graph 1 and Table 1.

Table 1. IR Spectrum Values for Charu prepared from Leaves of Acalypha indica

\begin{tabular}{|l|l|l|l|}
\hline Sr. No. & Wave Number $\left(\mathbf{c m}^{-\mathbf{1}}\right)$ & Functional group & Associated group \\
\hline 1 & $516.92-559.36$ & C-Br stretch & Alkyl halide \\
\hline 2 & $648.08-698.23$ & $-\mathrm{C} \equiv \mathrm{C}-\mathrm{H}:$ C-H Bend & Alkynes \\
\hline 3 & 783.1 & C-Cl Stretch & Alkyl halide \\
\hline 4 & $831.32-894.97$ & $\mathrm{~N}-\mathrm{H}$ way, C-H “loop & $1^{0}, 2^{0}$ amines, Aromatics \\
\hline 5 & 920.05 & $\mathrm{O}-\mathrm{H}$ bend & Carboxylic acid \\
\hline 6 & 1064.71 & $=\mathrm{C}-\mathrm{H}$ bend, $\mathrm{C}-\mathrm{N}$ stretch & Alkenes Aliphatic amines \\
\hline 7 & 1151.5 & $\mathrm{C}-\mathrm{O}$ stretch & Alcohols, esters, ethers \\
\hline 8 & $1336.6-1390.90$ & $\mathrm{~N}-\mathrm{O}$ symmetric stretch & Nitro compounds Aromatic amines \\
\hline 9 & 1540.2 & $\mathrm{~N}-\mathrm{O}$ asymmetric & Nitro compound \\
\hline 10 & 1660.20 & $\mathrm{~N}-\mathrm{H}$ bond & $1^{0}$ amines \\
\hline 11 & 3640.30 & $\mathrm{O}-\mathrm{H}$ stretch & h- bonded alcohols phenols \\
\hline
\end{tabular}

\subsection{Estimation of Trace \& Heavy Elements from Charu Prepared from Acalypha indica Leaves}

Material medica of Siddha system is mainly based on the metals and minerals of the drug hence 15 trace elements and heavy metals were estimated in present study (Table 2). Trace elements has key role in metabolism.

Table 2. Estimation of Some Trace and Heavy Elements from Charu Prepared from Leaves of Acalypha indica

\begin{tabular}{|l|l|l|l|}
\hline Sr.No. & Elements & Wavelength $(\mathbf{n m})$ & Concentration in ppm (Mean \pm SD $)$ \\
\hline 1 & Al & 176.641 & $497.79 \pm 0.11$ \\
\hline 2 & B & 249.773 & $37.24 \pm 0.04$ \\
\hline 3 & Ba & 455.404 & $21.28 \pm 0.001$ \\
\hline 4 & Cd & 214.438 & BDL \\
\hline 5 & Cr & 267.716 & BDL \\
\hline 6 & Cu & 324.754 & $10.08 \pm 0.001$ \\
\hline 7 & Li & 670.780 & BDL \\
\hline 8 & Ni & 231.604 & BDL \\
\hline 9 & Pb & 220.353 & $9.76 \pm 0.002$ \\
\hline 10 & Sr & 407.771 & $131.79 \pm 0.012$ \\
\hline 11 & Zn & 213.856 & $19.02 \pm 0.02$ \\
\hline 12 & As & 189.042 & BDL \\
\hline 13 & Hg & 184.95 & BDL \\
\hline 14 & Se & 196.09 & BDL \\
\hline 15 & Mo & 202.095 & BDL \\
\hline
\end{tabular}

(BDL= below detectable level) 
Table 3. Antifungal Activity of Charu prepared from Leaves of Acalypha indica

\begin{tabular}{|c|c|c|c|c|c|c|c|}
\hline \multirow{3}{*}{ Sr.No. } & \multirow{3}{*}{ Pathogenic fungi } & \multicolumn{4}{|c|}{ Colony diameter in mm } & \multicolumn{2}{|c|}{$\begin{array}{c}\text { Antifungal activity in \% } \\
\text { (\% of Inhibition) }\end{array}$} \\
\hline & & \multicolumn{2}{|c|}{$\begin{array}{c}\text { DMSO extract } \\
\text { of Charu }\end{array}$} & \multirow{2}{*}{$\begin{array}{c}\text { Standard positive } \\
\text { control (Griseofulvin) }\end{array}$} & \multirow{2}{*}{$\begin{array}{l}\text { Control } \\
\text { DMSO }\end{array}$} & \multirow{2}{*}{$\begin{array}{c}5 \% \text { DMSO } \\
\text { extract of Charu }\end{array}$} & \multirow{2}{*}{$\begin{array}{c}10 \% \text { DMSO } \\
\text { extract of Charu }\end{array}$} \\
\hline & & $5 \%$ & $10 \%$ & & & & \\
\hline 1 & Aspergillus niger & 19 & 16 & 00 & 42 & 54.76 & 61.90 \\
\hline 2 & Aspergillus flavus & 18 & 15 & 00 & 24 & 25.00 & 37.50 \\
\hline 3 & $\begin{array}{c}\text { Penicillium } \\
\text { Chrysogenum }\end{array}$ & 5 & 5 & 00 & 19 & 73.68 & 73.68 \\
\hline 4 & $\begin{array}{l}\text { Fussarium } \\
\text { moneliforme }\end{array}$ & 9 & 7.5 & 00 & 24 & 62.5 & 68.75 \\
\hline
\end{tabular}

\subsection{Antifungal Activity of Charu Prepared from Leaves of Acalypha indica}

From the results presented in Table 3, it is clear that maximum antifungal activity was observed in $5 \%$ and $10 \%$ DMSO extract of Charu on Penicillium chrysogenum i.e. 73.68\%, followed by Fusarium moneliforme (62.5\% and $68.75 \%$ for $5 \%$ \& $10 \%$ respectively) as compared with control. It can be also noted that antifungal activity of extract is more than $50 \%$ on Aspergillus niger but it showed less activity against A.flavus. Standard control shows $100 \%$ antifungal activity against all pathogenic fungi (Table 3).

\section{Discussion}

IR Spectrum result showed the presence of numerous functional groups in all plants. The main functional group was found are $\mathrm{C}=\mathrm{O}$ carbonyl group, $\mathrm{C}-\mathrm{O}$ group $\mathrm{C}=\mathrm{C}$ group $\mathrm{C}-\mathrm{H}$ stretching $-\mathrm{OH}$ group, $\mathrm{CHO}$ group with associated group like alkyl halides, aromatic compounds, alkaloids, aldehydes, phenols, carboxylic acids, amines etc (Graph 1, Table 1). Previously elemental analysis of leaves of $A$. indica was carried out [11] and the result obtained for elemental analysis of Charu revealed that there is no significant difference in the trace and heavy elemental contents of leaf powder of $A$. indica and the Charu prepared from it. Heavy elements like Arsenic, Mercury, were not detected except Lead. Lead is poisonous element for consumption, it causes serious health problems but according to WHO guideline daily intake of $\mathrm{Pb}$ for 3-4 $\mu \mathrm{g} / \mathrm{kg}$ of body weight is permissible for all age groups and it was not associated with an increase in blood lead levels or in the body burden of lead and hence can be used as drug in some extent [20]. Trace and heavy Elemental analysis from this drug (Table 2) shows good results for most of trace and heavy elements which has great significance siddha system of medicine. Previously antifungal activity of methanol extract of leaf of $A$. indica was studied on A.niger and Candida sp., it shows zone of inhibition 6.88 $\mathrm{mm}$ for A. niger [21]. Antifungal activity of ethanol extract of Acalypha indica against $A$. flavus and $P$. chrysogenum shows significant activity whereas extract do not show zone of inhibition against $A$. niger [22]. The results of present work on antifungal activity revealed that the Charu extract significantly inhibit the growth of P.chrysogenum, F. Moneliforme and A. niger. In GC-MS analysis of Acalypha indica Leaves, Proline 3,4-didehydro-, Cysteine, 1H-Pyrrole-2,5-dione,1- ethenyl-, 3,8-Nanodiene-2-one, (E)-, 4-Amino-3-methoxypyrazolo[3,4-d] pyrimidine, Propanenitrile, 3-(5-diethylamino-1methoxy-3-pentynyloxy)- and Kaempfeorl compounds are observed [23]. Hence it can be revealed that these compounds may have effective antifungal potential against the studied non-dermatophytic fungi.

\section{Conclusions}

FTIR spectrum analysis shows presence of wide range of compounds with different functional groups. Presence of $\mathrm{Al}, \mathrm{Cu}, \mathrm{B}, \mathrm{Zn}$ and $\mathrm{Sr}$ in appreciable quantity indicates antimicrobial potential of Acalypha indica. Antifungal activity of Charu shows effective results against the studied nondermatophytic infectious fungal species, it consists of an important phytocompounds which having antifungal potential. The present study provides the scientific basis for usefulness of Acalypha indica and its formulated drug Charu against skin diseases caused by fungal pathogens.

\section{REFERENCES}

[1] CK Kokate, AP Purohit and SB Gokhale. Pharmacognosy: Nirali Prakashan, Pune; 2009.

[2] R. Arjun, AJ. Duraisamy, B. Selvakumar, PS. Vijay. Medicinal plants from Siddha system of medicine useful for treating respiratory diseases. International Journal of Pharmaceuticals Analysis:1(2);20-30, 2009.

[3] A. Mathur, H. Joshi. Ethnobotanical studies of the tarai region of kumaun, uttarakhand, India. J Ethnobotany research \& applications, Vol. 11, 175-203, 2013.

[4] SB. Padal, P. Chandrasekhar and Y. Vijaykumar. Traditional 
uses of plants by tribal communities of salugupanchayati of paderumandalam, visakhapattnam district, Andhra Pradesh, India. Inter. J. Computational Engi. Res, Vol. 3(5), 98-103, 2013.

[5] A. Shirwaikar, K. Rajendran, R. Bodia, CD. Kumar. Neutralization potential of Viper russelli (ressels viper) venom by ethanol leaf extract of Acalypha indica. J. Ethnopharmacol, Vol. 94, 267-273, 2004.

[6] A. Azmahani, MN. Somchit \& AR. Rosyilah. In vitro antibacterial and antifungal properties of Acalypa indica (kucinggulak). Symposium dengantema proceedings of the regional symposium of environment \& natural resources tangal, Kualalampur, Malysia, Vol. 1, 503-508, 2008.

[7] KR. Durga, S. Karthikumar and K. Jagatheesan. Isolation of potential antibacterial and antioxidants compounds from Acalypha indica and ocimum basillicum: J Med Plant Res. Vol. 3(10), 703-706, 2009.

[8] M. Govindrajan, A. Jabanesan, D. Reetha, R. Amsath, T. Pushpanathan and K. Samidurai. Antibacterial activity of Acalypha indica L. Eur Rev Med Pharmacol Sci., Vol. 12(5), 299-302, 2008.

[9] RG. Marwah, MO. Fatope, RA. Mahrooqui, GB. Verma, HA. Abadi and SKS. Al-Burtamani. Antioxidant capacity of some edible and wound healing plants in Oman. Food Chem., Vol. 101(2), 465-470, 2007.

[10] RDJ. Solomon, S. Kallidas and J. Vimalan. Isolation, identification and study of antimicrobial property of a bioactive compound in an indian medicinal plant A.indica; World J Microb. Biot., Vol. 21, 1231-1236, 2005.

[11] SK. Umate and VR. Marathe. Nutraceutical evaluation of Acalypha indica L. - A potential wild edible plant. International Journal of Green Pharmacy, Vol. 12 (3 Suppl.), 510-517, 2018.

[12] M. Muthaliar. Materia Medica (Vegetable section), Fourth edition, Volume I: publisher, Tamilnadu Siddha Medical Council, Chennai. pp 359, 1988.

[13] A. Bose, DE. Krishanu, S. Vikas. A Review on Latest Developments in the Standardization of Ayurvedic Drugs. International Journal of Pharmaceutical Research and Bio-science, Vol. 1(3), 96-119, 2012.

[14] G. Moreno and R. Arenas. Other fungi causing Onychomychosis. Clin Dermatol, Vol. 28, 160-163, 2010.

[15] S. Bassiri-Jahromi, AA. Khaksar. Nondermatophytic moulds as a causative agent of Onychomychosis in Tehran. Indian J Dermatol, Vol. 55, 140-143, 2010.

[16] Dong Min Kim, Moo Kyu Suh, Gyoung Yim Ha, Seung Hyun Sohng. Fingernail Onychomychosis Due to Aspergillus niger. Ann Dermatol, Vol. 24(4), 459-463, 2012.

[17] VN. Naik. Flora of Marathwada, Vol. 1 and 2, Amrut Prakashan, Aurangabad; 1998.

[18] SS. Shukla, S. Saraf, S. Saraf. Fundamental aspect and basic concept of siddha medicines. Syst Rev Pharm., Vol. 2(1), 48-54, 2011.

[19] M. Balouiri, M. Sadiki, SK. Ibnsouda. Methods for in vitro evaluating antimicrobial activity: A review. Journal of
Pharmaceutical Analysis, Vol. 6, 71-79, 2016.

[20] Anonymous. Evaluation of certain food additives and contaminants: forty-first report of the Joint FAO/WHO Expert Committee on Food Additives. Geneva, World Health Organization; 1993.

[21] C. Sudhakar, B. Arun Jyoti, S. Saraswathi. Evaluation of antimicrobial and antifungal activity of Acalypha indica L., leaf extract. International Journal of Pharmacognosy and Phytochemical Research, Vol.10 (1), 48-51, 2018.

[22] P.Saranraj, S. Siva Sakthi and M.Geetha. Pharmacological Screening of Datura metel and Acalypha indica for its antifungal activity against pathogenic fungi. International journal of pharmaceutical science and health care, Vol. 2(1), 15-29, 2011.

[23] A. Zahir Hussain and S. Kumaresan. GC-MS analysis and antibacterial evaluation of Acalypha indica. Asian Journal of Plant Science and Research, Vol. 3(6), 46-49, 2013. 